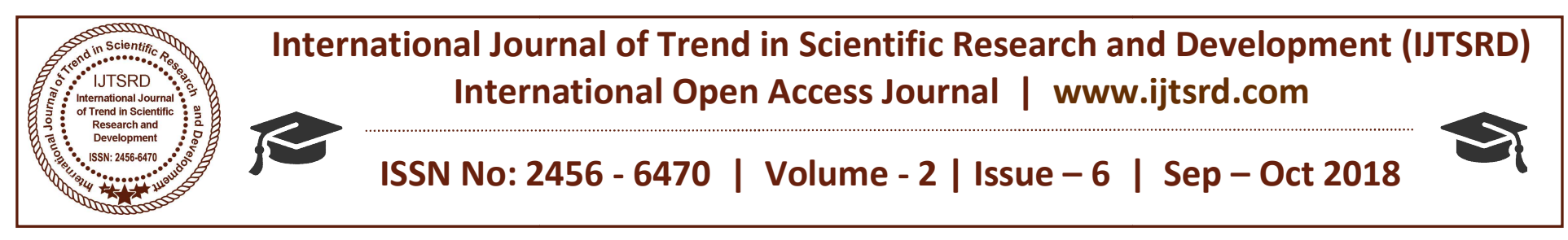

\title{
Design and Construction of an Electric Arc Welding Machine's Transformer
}

\author{
ASIWE Uchechukwu, Edema Anthony, Edeafeadhe Godspower \\ Electrical/Electronic Engineering Department, Delta State Polytechnic, Otefe-Oghara, Nigeria
}

\begin{abstract}
Arc welding machine is the type machine that uses an electric power as an input, which is being supplied through the primary and then transferred to the secondary winding by induction which can be used to carry out welding work by connecting to the output terminal the welding cables. The output of the machine is designed in a way that it can be varied by adjusting the crank of the machines in clockwise or anti-clockwise direction in either to increase or decrease the output current respectively depending on the size of the material it is to be used on. The major component of the machine that carry out such function is the transformer. This paper focuses on the design and construction of the welding machine transformer. The transformer is single phase which has shell type of lamination core and insulated windings of copper coils. In addition, the windings are given double insulation with the use of varnish solution which helps to prevent short-circuiting in the windings. With the help of Angle iron and lamination core, the core loss, iron loss in the machine is reduced to minimum. The voltage in (Vin) was determined directly from the mains of power supply and recorded. The voltage out (Vout) was recorded when the transformer was connected to the power supply at zero load while the scaling factor is the ratio of the output voltage and input voltage. The turn factor was also calculated to determine the relationship of the turn given to the transformer and the scaling factor. It was also observed that the scaling factor and the turn factor at terminal $\mathrm{A}$ is almost the same, this shows that the higher the turns the better the transformer to avoid high current which may cause spark and also improving the efficiency.
\end{abstract}

Keyword: Primary Coil, SecordaryCoil, Current and Welding

\section{INTRODUCTION}

Welding is a fabrication process that joins materials usually metals or thermoplastics, by causing coalescence. The most popular of the welding machines uses the arc welding methods (Catarina, 2014).

Arc welding is a process that is used to join metal to metal by using electricity to create enough heat to melt metal, and the melted metals when cool result in a binding of the metals. It is a type of welding that uses a welding power supply to create an electric arc between an electrode and the base material to melt the metals at the welding point. Arc welding processes may be manual, semi-automatic, or fully automated.

Sir Humphry Davy (1800) was the first to discover the short pulsed electric arcs. Arc welding was first developed when Nikolai Benardos (1881) presented arc welding of metals using a carbon electrode at the (Kalpakjian and Schmid, 2001).

The Arc welding machine is the type that uses an electric power as an input, which is being supplied through the primary and then transferred to the secondary winding by induction which can be used to carry out welding work by connecting to the output terminal the welding cables. The output of the machine is designed in a way that it can be varied by adjusting the crank of the machines in clockwise or anti-clockwise direction in either to increase or decrease the output current respectively depending on the size of the material it is to be used on (Takasaki et al., 2003).

Due to the vast need and use of iron rods, metal bars and pipes, right from the domestic level up to industrial extent, the electric arc welding machine was built in order to ensure that the ulterior motive of the 
manufacturers of these products (iron rods, metal bars and pipes) by their manufacturers is being achieved as part of technological advancement. With the Construction of Electric Arc welding machines, the difficulty of using iron rods, bars and pipes in construction works will be removed.

The electric welding machine can be used in permanent joining metal parts. In this process, heat is applied to metal pieces, melting and fusing them to form a permanent bond. Because of its strength, electric welding is used to join beams when constructing buildings, bridges, and other structures, and to join pipes in pipelines, power plants at the construction sites. Also, it can be used in the home welding applications and thousands of other manufacturing activities. Furthermore, the electric welding machine can be used in shipbuilding, automobile manufacturing and repair applications. The welding in which the electric arc is produced to give heat for the purpose of joining two surfaces is called Electric arc welding. The electric welding machine can be used in permanent joining metal parts. In this process, heat is applied to metal pieces, melting and fusing them to form a permanent bond. Because of its strength, electric welding is used to join beams when constructing buildings, bridges, and other structures, and to join pipes in pipelines, power plants at the construction sites. Also, it can be used in the home appliance and thousands of other manufacturing activities. Furthermore, the electric welding machine can be used in shipbuilding, automobile manufacturing and repair applications (Lincoln, E (1994),

\section{Basic Principle of Electric Welding Machine}

Power supply is given to electrode and the work. A suitable gap is kept between the work and the electrode. A high current is passed through the circuit. An arc is produced around the area to be welded. The electric energy is converted into heat energy, producing a temperature of 3000 to $4000 \mathrm{C}$. This heat melts the edges to be welded and the molten pool is formed. On solidification the welding joint is obtained (Evbogbai and Enoch 2002).

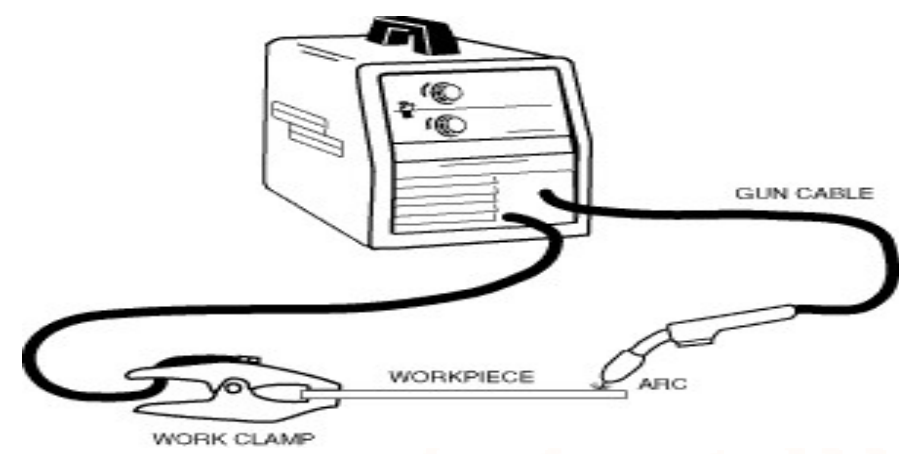

Fig. 1: Electric welding machine

\section{Welding transformer set:}

The major component of the electric arc welding machine is the transformer. The unit consists of the following main components single phase transformer (with tap changing secondary). The transformer is a step-down transformer with different tapping at $\mathrm{H}, \mathrm{M}$ and L; welding tung cables.

The transformer is a conventional-cooled, single phase transformer which has shell type of lamination core and insulated windings of copper cols. In addition, the windings are given double insulation with the use of varnish solution which helps to prevent short-circuiting in the windings.(Charles et al., 2000).

With the help of Angle iron and lamination core, the core loss, iron loss in the machine is reduced to minimum. They also help to reduce humming in the machine. Hence, efficiency of the machine is greatly improved.

It is used to step down the voltage supply. It consists of primary and secondary circuits. The input is given to primary windings. By electromagnetic induction the current flows through the secondary coil (Bharat, 2003). The transformer output can be controlled as per requirement. A combination of primary and/or secondary taps on the welding transformer is commonly used to provide a macro adjustment of the welding current, as well as adjustment of secondary voltage. Transformer ratings for AC machines are expressed in KVA (kilovolt-amperes) for a specified duty cycle. (Takasaki, et al (2003). 


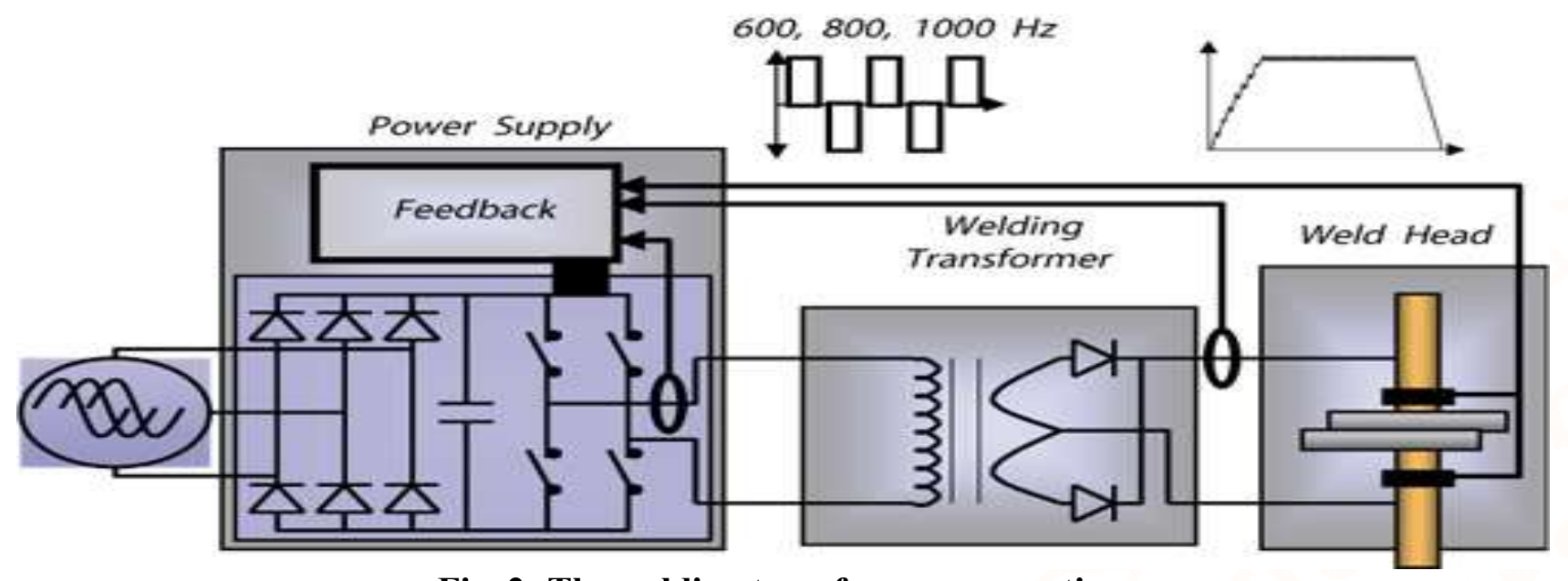

Fig. 2: The welding transformer connection

The primary voltage coming into the machine is too high for safe welding. Therefore, it is stepped down to a useable voltage. The Welding transformer consists of a step-down transformer with a tapped secondary having an adjustable reactor in series with it for obtaining drooping $\mathrm{V} / \mathrm{I}$ characteristics. The secondary is tapped to give different voltage/current settings (Catarina, 2014).

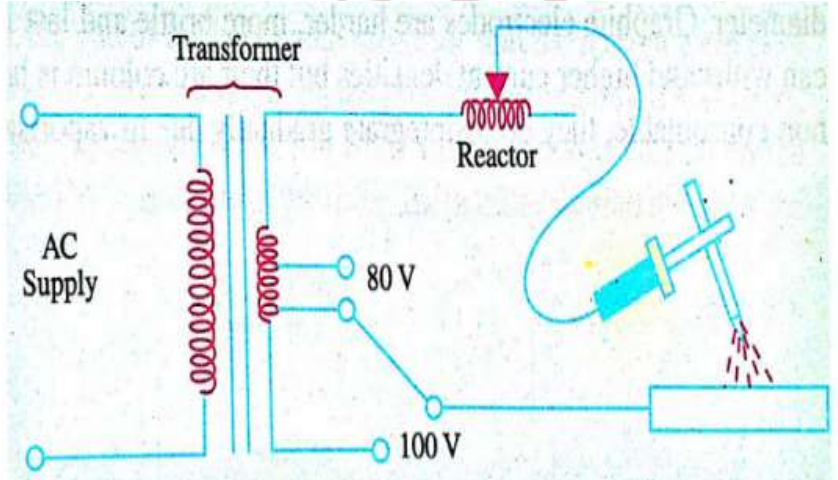

Fig.3: Welding transformer circuit (Bharat, 2003).

Working of an Electric Arc Welding Transformer An electrical current can be induced into a conductor when a conductor is moved through a magnetic field to produce alternating current. If this alternating current is passed through a conductor, a pulsating magnetic field will surround the exterior of that conductor that is the magnetic field will build in intensity through the first 90 electrical degrees, or the first cycle. From that point, the magnetic field will decay during the next quarter cycle until the voltage or current reaches zero at 180 electrical degrees. Immediately, the current direction reverses and the magnetic field will begin to build again until it reaches a maximum at 270 electrical degrees in the cycle. From that point the current and the magnetic field again begin to decay until they reach zero at 360 electrical degrees, where the cycle begins again. If that conductor is wound around a material with high magnetic permeability (magnetic permeability is the ability to accept large amounts of magnetic lines of force) such as steel, the magnetic field permeates that core. This conductor is called the primary coil, and if voltage is applied to one of its terminals and the circuit is completed, current will flow. When a second coil is wound around that same steel core, the energy that is stored in this fluctuating magnetic field in the core is induced into this secondary coil. It is the build-up and collapse of this magnetic field that excite the electrons in the secondary coil of the transformer. This causes an electrical current of the same frequency as the primary coil to flow when the secondary circuit is completed by striking the welding arc (Goueishankar, 2004).



BASIC TRANSFORMER

Fig.4: Basic transformer circuit

\section{Construction and Analysis of the Welding Transformer}

The A.C welding machine design is a two pole circuit, with the first pole been the primary circuit and the second pole is the secondary circuit.

\section{The Primary Circuit (pole 1)}

The primary circuit was design to vary in current selection without tempering with the coil itself; it has a four step coil with three looping for the selection of current capacity. 


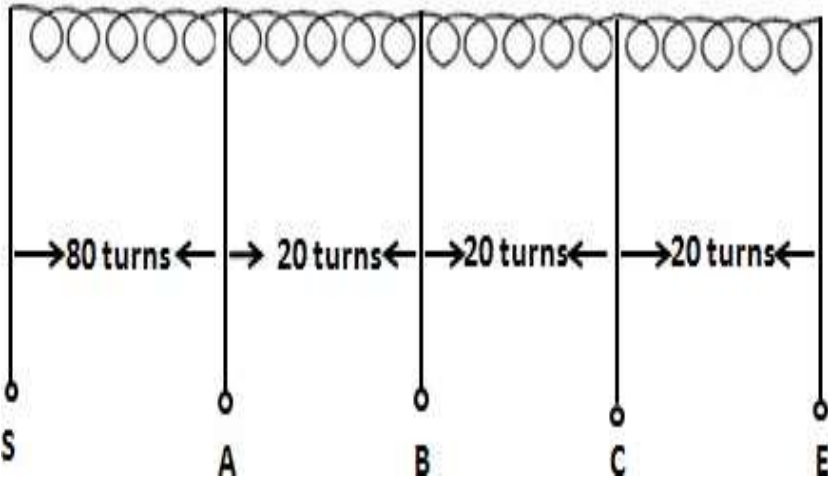

Fig 5: A circuit showing the four step circuit and the looping for the current selection

In the primary circuit the winding begins at the start point $\mathrm{S}$ and was given 80 turns with a copper wire of size gauge 13. The first looping was introduced after the first winding and was labeled $\mathrm{A}$, the winding continues with same size gauge for another 20 turn before the second looping labeled B. The third looping $\mathrm{C}$ and the last winding labeled $\mathrm{E}$ was given 20 turns each with same size wire gauge 13. The beginning of the wire marks the starting point , $\mathrm{S}^{\prime \prime}$ and the end of the wire marks the ending point ", $E^{\prime \prime}$, both point are used for connection purposes. nternatio

\section{The Secondary Circuit (Pole2)}

The second circuit was design to consist of two coils over lapping each other. The first coil is the primary coil wound with 114 turn's size wire gauge 13 while the secondary coil was 40 turn of tick size wire gauge 8 as shown in figure 2 . The starting point and ending point of the secondary coil serve as the welding terminals.



Fig 6: A circuit showing the secondary circuit with the over lapped primary circuit.

\section{The Core}

The core is made of laminations assembled to provide a continuous magnetic path with a minimum of air gap included. The lamination steel help to minimize eddy current loss and the thickness of the lamination varies from $0.35 \mathrm{~mm}$ for a frequency of $50 \mathrm{~Hz} 0.5 \mathrm{~mm}$ for a frequency of $25 \mathrm{~Hz}$.

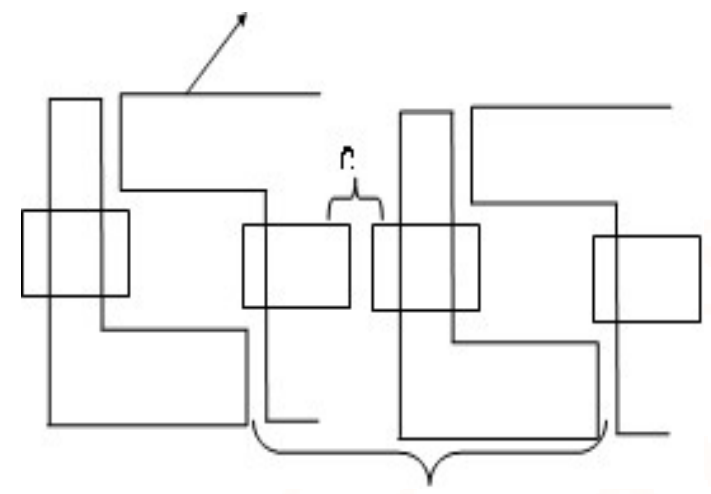

Fig 7: Diagrams showing the arrangement of a laminated core on the coil

\section{Copper on the Coil}

Copper wire is of more advantage in winding process than that of aluminum. Copper wire has more capacity and strong enough to resist the function of any kind of winding for a longer time. It has different type of gauge and is coated with insulator to prevent contact of wires when winding.

For the aluminum wire its very effective when used than the copper wire, it produces stronger magnetic flux which makes the machine more powerful. The disadvantage of an aluminum wire is that they are not insulated thereby need proper insulation before it can be used for winding.

\section{Insulators}

Insulators are materials that do not conduct electricity in any form. They are used to separate two wires to avoid partial contact of any form.

\section{Construction}

In the construction, the laminated core was arranged first to form the two poles as shown fig 8 .

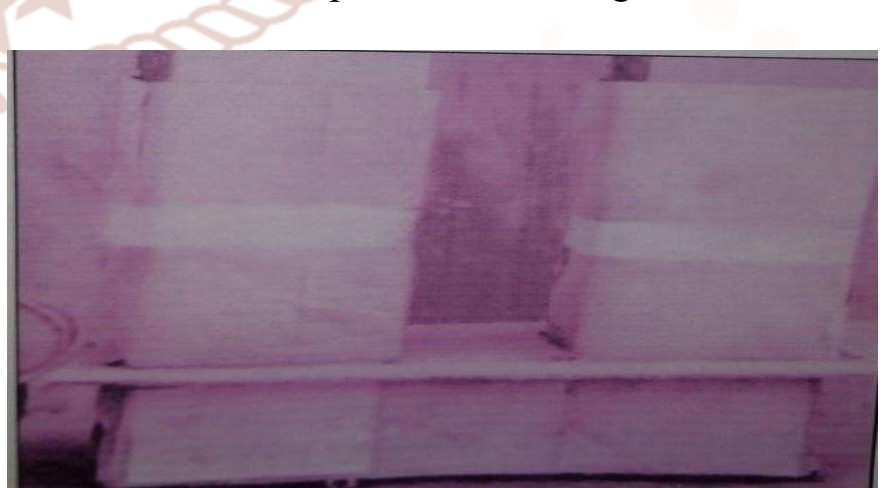

Fig 8: Diagrams showing the formation of the two poles laminated stand

The total laminated core used for the I stand pole was 480 and that of $\mathbf{L}$ shape was a total of 480 , given and a net total of 960 laminated core used in all. 
In the winding, the shape of the laminated core was taken and a core was form for the winding of the coil as shown in fig.9

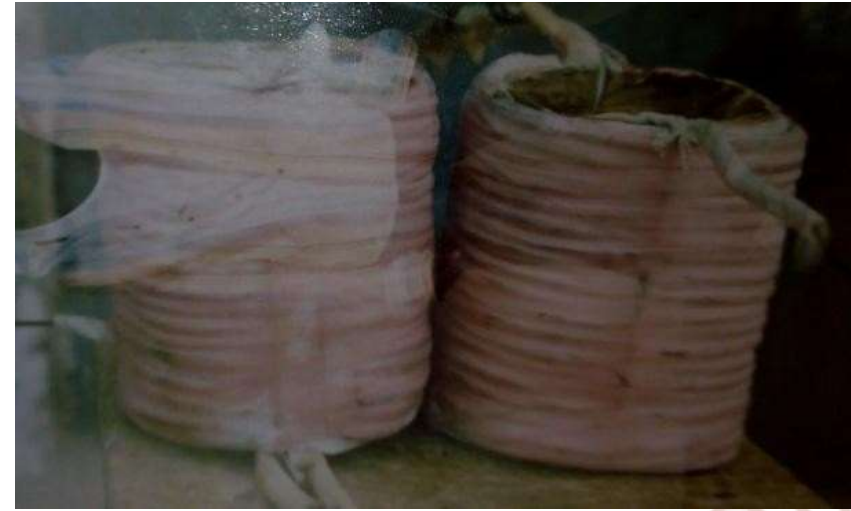

Fig 9: A Diagram showing the coil and the winding shape with respect to the laminated core.

The next step was the fixing of the coil in the pole and the crossing of the top of the machine with a laminated core to avoid Butt joint. The complete construction work is as shown in the fig. 10.



Fig 10: A Diagram showing the complete coupled construction work of the welding machine.

\section{Connections}

The major kinds of connections that can be given to this construction include:

A. Star-delta connection or End to start connection

B. Star - star connection or start to start connection

C. Delta-Delta connection or End to End connection

The type of connection use in this work is the start to start connection; it involves the starting wire hand of the primary circuit connected to the secondary circuit as shown in fig 11 .

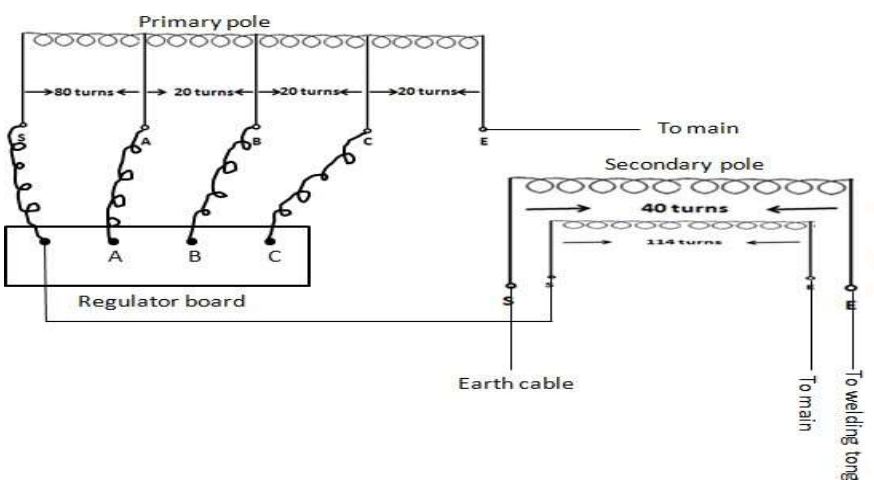

Fig 11: A circuit diagram showing the detail connection of the primary circuit.

Owing to the connection between the primary pole and the secondary pole, the primary turns will toggle with respect to the variation of the current thus, 254 turns from $\mathrm{S}$ to $\mathrm{A}, 174$ turn from A to B, 154 turns from $\mathrm{B}$ to $\mathrm{C}$ and 114 turns from $\mathrm{C}$ to $\mathrm{E}$.

At the secondary circuit, the starting hand is connected to the earth of the welding side and the end hand connected to the tong bearing the electrode.

\section{Welding Power Source}

A welding power supply is a device that provides an electric current to perform welding. Welding usually requires high current (over 80 amperes) and it can need above 12,000 amperes in spot welding. Low current can also be used; welding two razor blades together at 5 amps with gas tungsten arc welding is a good example (Evbogbai and Enoch, 2002).

\section{Testing}

The testing of the machine confirmed the success of the design, construction and connection of the work, as there was no spark or shock from the laminated core and when connected to the welding apparatus, it was used for joining metals without any problem.

In the testing, the voltages at zero load and when in operation was measured and recorded as shown in the result below.

\section{Result}

Being a variable transformer selection type, the current at both input and output of the transformer were determined thus; 
International Journal of Trend in Scientific Research and Development (IJTSRD) ISSN: 2456-6470

Table1: Showing the input and output voltage values from the electric welding machine

\begin{tabular}{|c|c|c|c|c|c|c|}
\hline Terminals & Pri turn $\left(\mathbf{N}_{\mathbf{P})}\right.$ & Sec. turn $\left(\mathbf{N}_{\mathbf{s}}\right)$ & Vin $\left._{\mathbf{V}}\right)$ & $\mathbf{V}_{\text {out }}(\mathbf{V})$ & $\begin{array}{c}\text { Scaling Factor } \\
\mathbf{V}_{\text {out }} / \text { Vin }\end{array}$ & $\begin{array}{c}\text { Turn factor } \\
\mathbf{N} / \mathbf{N p}\end{array}$ \\
\hline A & 254 & 40 & 240 & 37 & 0.154 & 0.157 \\
\hline B & 174 & 40 & 240 & 41 & 0.171 & 0.230 \\
\hline C & 154 & 40 & 240 & 45 & 0.190 & 0.260 \\
\hline D & 114 & 40 & 240 & 50 & 0.208 & 0.351 \\
\hline
\end{tabular}

The voltage in $\left(\mathrm{V}_{\text {in }}\right)$ was determined directly from the mains of power supply and recorded. The voltage out $\left(\mathrm{V}_{\text {out }}\right)$ was recorded when the transformer was connected to the power supply at zero load while the scaling factor is the ratio of the output voltage and input voltage. The turn factor was also calculated to determine the relationship of the turn given to the transformer and the scaling factor as shown above.

\section{Discussion}

The result shows that the scaling factor and the calculated turn factor differ with the range of 0.275 which dictates the transformer losses during operation. These losses range from eddy current losses, winding resistance losses, hysteresis losses and mechanical losses.

It was also observed that the scaling factor and the turn factor at terminal A is almost the same, this shows that the higher the turns the better the transformer to avoid high current which may cause spark and may consequently lead to fire outbreak. The determination of the various input and output current enable the user to vary the current in supply and also use the appropriate volts for the welding desire.

\section{Conclusion}

In the use of welding machine the challenges observed is the power quality problems and the leakage of a welding transformer. This paper work was to construct a welding machine transformer that can essentially maintain the constant current supply desired to check or solve the power quality problems associated with the welding process and to improve on the leakage through the turn ratio given to the transformer. In the course of the construction the role of the turns given to a transformer was fascinating, as it shows that the higher the turns, the more efficient the transformer as stated in the discussion above. The electric welding machine can be used in permanent joining metal parts. Because of its strength, the electric welding can be used to join beams when constructing buildings, bridges, and other structures, and to join pipes in pipelines, power plants at the construction sites.

\section{REFERENCES}

1. Bharat, K (2003). Transformers. $2^{\text {nd }}$ Edition. Tata McGraw-Hill publishing company Limited, New Delhi, pp 292.

2. Catarina, S (2014). Finite Element Analysis of a Welding Transformer. vol. 18, no. pp. 212-221.

3. Charles, J. P., Khoury, A., and Hoffmann, A (2000). New Design Method for Controlling Power Stages Based on IGBT Switching Ferrite Transformers: Applied to an 8kW Small Size Light $/ /$ Weight Electric Welding Machine, Electronics, Circuits and Systems. The 7th IEEE International Conference. Volume 2, 17-20 pp. $802-804$

4. Evbogbai, J. E. and Enoch A M., (2002).Design and Construction of Alternating Current Welding Machine Using Locally Available Matenals. Global J. Mech. Eng., 3: 74-83.

5. Goueishankar, V (2004). Electromechnical energy conversion. Int. Text Bock Company, Pennsylvania, pp: 156.

6. Kalpakjian, $\mathrm{S}$ and Schmid, S.R. (2001), Manufacturing Engineering and Technology, Prentice-Hall, ISBN 0-201-36131-0

7. Lincoln, E (1994), The Procedure Handbook of Arc Welding, Cleveland, Ohio: Lincoln Electric, pp: 124

8. Takasaki, Y., Sonoda, T and Fujii, S. (2003). Development of a portable spot-welding machine, Magnetics Conference. IEEE International Conference. pp. 66 